\title{
Herpes Gestationis
}

\author{
IMMUNOPATHOLOGY AND CHARACTERIZATION \\ OF THE HG FACTOR
}

\author{
Stephen I. Katz, Kenneth C. Hertz, and Hideo Yaotta \\ From the Dermatology Branch, National Cancer Institute, National Institutes \\ of Health, Bethesda, Maryland 20014
}

\begin{abstract}
A в S T R A C T Five patients with herpes gestationis, a blistering disease of pregnancy, were studied immunologically. All had in vivo deposition of C3 in a linear band along the basement membrane zone of lesional and normal-appearing skin, the location of early blister formation. Immunoglobulin deposition was more variable, though four patients had evidence of in vivo bound IgG at the same site. A circulating, complement binding herpes gestationis factor was demonstrated in the sera of four of the patients, its concentration unrelated to the activity of clinical disease. Characterization of this factor by sucrose gradient ultracentrifugation, specific absorption studies, and papain digestion indicates that it is an IgG. Evidence exists for involvement of both the classical and alternate complement pathways in vivo, though in vitro studies implicate the classical pathway as the primary route of complement activation. Three offspring were studied, none with clinical involvement; one showed in vivo deposition of C3 at the basement membrane zone of normal skin and a second showed the herpes gestationis factor in cord blood.
\end{abstract}

\section{INTRODUCTION}

Herpes gestationis $(\mathrm{HG})^{1}$ is a rare, recurrent, intensely pruritic, subepidermal blistering disease which occurs during pregnancy or shortly thereafter. It had been considered a variant of erythema multiforme or dermatitis herpetiformis until Provost and Tomasi demonstrated HG to be a distinct disease (1). They studied two patients with $\mathrm{HG}$ and found, on direct immunofluorescence

Recciv'cd for publication 5 November 1975 and in revised form 3 February 1976.

${ }^{1}$ Abbreviations used in this paper: $\mathrm{BM}$, basement membrane; BP, bullous pemphigoid; EGTA, ethyleneglycoltetracetic acid; factor $B$, properdin factor B; FITC, fluorescein isothiocyanate; HG, herpes gestationis; IF, immunofluorescence; NFS, normal fresh serum ; $\mathrm{P}$, properdin; PBS, phosphate-buffered saline.
(IF), basement membrane (BM) deposition of the third component of complement (C3) in the skin of both patients. Properdin and $\mathrm{C} 5$ were also detected at the $\mathrm{BM}$ zone of the skin of one of their patients; $\mathrm{Clq}$, immunoglobulins, or light chains were not found. In addition, a thermolabile, humoral factor called $\mathrm{HG}$, which was thought not to be an immunoglobulin by partial characterization, was detected in the sera of both patients. Their studies indicated the activation of $\mathrm{C} 3$ by this $H G$ factor via the alternate pathway, in the absence of demonstrable circulating antibodies.

Nine other patients have been studied and all had at least C3 bound in vivo at the BM zone (2-4). Six of these patients had Ig deposition at the same site, and circulating BM antibodies were not demonstrable in their sera. Bushkell et al. (5) reported another $\mathrm{HG}$ patient whose lesions showed deposition of IgG, C1q, C3, and properdin at the BM zone on direct immunofluorescence. This patient, unlike the others, had a circulating antibody to BM at a titer of 320 .

We have studied the sera and tissues of five patients with HG. In each patient there was a linear deposition of $\mathrm{C} 3$ in addition to other complement components at the BM zone of skin, which is the site of early and major pathology. The sera of all of these patients contained the $\mathrm{HG}$ factor, which deposited fresh $\mathrm{C} 3$ onto the $\mathrm{BM}$ of normal human substrate in an in vitro complement binding test. Our characterization of the HG factor defines it as an IgG and suggests that its in vitro activation of C3 is mainly via the classical pathway. This report will (a) detail this characterization of the $\mathrm{HG}$ factor, (b) describe the direct IF findings in lesional and normal appearing skin, and $(c)$ describe serum and skin studies of three of the infants born to three of the patients.

\section{METHODS}

Paticnts. The sera and tissues of five patients with $\mathrm{HG}$ were studied. Clinical summaries and histopathologic fea- 
tures of the lesions of the first three patients are detailed elsewhere (5A). Briefly, patient 1 (Y. A.), a 33-yr-old black woman, experienced her second episode of $\mathrm{HG}$ during the fourth month of her second pregnancy. The extremely pruritic eruption consisted of widespread, papulovesiculobullous lesions. Biopsy showed subepidermal vesicles with an intense infiltrate consisting primarily of neutrophils and eosinophils, pronounced edema of the upper dermis, and a moderate, perivascular infiltration of mixed cellularity. Symptoms abated within $24 \mathrm{~h}$ of treatment with $10 \mathrm{mg}$ prednisone four times daily, and the eruption resolved in 7 days. Occasional itching and infrequent lesions recurred while she was maintained on $20-30 \mathrm{mg}$ prednisone for the duration of pregnancy. A $3 \frac{1}{2}$-pound, normal female child was delivered by Caesarian section during the 31 st week of gestation. 4 mo postpartum, after being free of lesions for 3 mo and off treatment for $1 \mathrm{mo}$, the patient was given Ortho-Novum $1 / 50$ (1 $\mathrm{mg}$ norethindrone and $0.05 \mathrm{mg}$ mestranol, Ortho Pharmaceutical Corp., Raritan, N. J.) and 17 days later developed a few lesions, similar both morphologically and histologically to the original eruption.

The second patient (N. C.), a 37-yr-old white woman, developed pruritic vesicular lesions on her left leg 2 days after delivery. These rapidly progressed to involve all extremities and trunk with vesicles and small urticarial plaques in a spotty distribution. Biopsy of a vesicular lesion showed a subepidermal blister and a dense, mononuclear, perivascular infiltrate. Over the next 3 mo the eruption completely cleared without treatment.

Patient 3 (C. S.), a 28-yr-old white woman, had a prior history of a postpartum, vesiculobullous eruption, diagnosed retrospectively as HG. In the fifth month of her second pregnancy, she developed severe pruritis and a widespread blistering eruption on the abdomen and all extremities. Biopsy showed a subepidermal blister with a heavy infiltrate of eosinophils, neutrophils, and mononuclear cells. There were similar infiltrates in adjacent papillae and around the blood vessels of the superficial dermis. Treatment with $10 \mathrm{mg}$ of prednisone every $6 \mathrm{~h}$ controlled her itching and led to clearing of the eruption within 7-10 days. She was maintained on decreasing doses of prednisone and delivered a full-term, normal, female child. During the puerperium she developed a few transitory lesions.

Patient 4 (D. T.), a 34-yr-old Puerto Rican woman, developed a vesiculobullous eruption on her trunk and extremities in the fourth month of her second pregnancy. Histology showed a subepidermal blister and a perivascular infiltrate. She was successfully treated with $60 \mathrm{mg}$ of prednisone a day; approximately $1 \frac{1}{2}-2$ wk after the onset of her disease she had a spontaneous abortion.

Patient 5 (M. B.), a 27-yr-old white woman in the last month of her first pregnancy, developed edematous, red, pruritic papules with peripheral vesicles on the abdomen, thighs, and legs. Histology of nonbullous, lesional skin showed edema and a predominantly perivascular infiltrate consisting of mononuclear cells and neutrophils. Her symptoms were somewhat relieved with topical, fluorinated steroids.

Immunofuorcsccnt methods. Direct IF and modified direct IF methods were used to detect in vivo bound IgG, $\operatorname{IgA}, \operatorname{IgM}$, IgE, and $\mathrm{IgD}$, and $\mathrm{Clq}, \mathrm{C} 4$, properdin $(\mathrm{P})$, properdin factor B (factor B), C3, and C5. Direct IF was performed with commercially obtained fluorescein isothiocyanate (FITC) labeled, goat antihuman IgG, IgM, IgA, and IgE (all from Hyland Div., Travenol Laboratories, Inc., Costa Mesa, Calif.) ; C1q and C4 (both from Meloy Lab- oratories, Springfield, Va.); and C3 (Travenol Laboratories, Inc.). The $\mathrm{F} / \mathrm{P}$ ratios were between 2.3 and 3.6 , and the antibody concentration for use varied between 20 and $50 \mu \mathrm{g}$ of specific antibody protein per milliliter. The modified direct IF technique was used for $\operatorname{IgD}, \mathrm{P}$, factor $\mathrm{B}$, and $\mathrm{C5}$, where unlabeled rabbit antihuman $\operatorname{IgD}$ (Meloy Laboratories), rabbit antihuman factor B (Behring Diagnostics, American Hoechst Corp., Somerville, N. J.), and goat antihuman C5 (Meloy Laboratories) were obtained commercially. Rabbit antihuman $P$ was prepared by injecting rabbits with purified $P$ (in complete Freund's adjuvant), obtained from Dr. A. Kaplan, and absorbing the antiserum with a solid phase immunoabsorbant of human serum, which had been twice previously treated with zymosan at $17^{\circ} \mathrm{C}$ for $30 \mathrm{~min}$ (6). The purity and specificity of all of the antisera were checked by double diffusion in agar and by immunoelectrophoresis. The purity of the rabbit antihuman $P$ was demonstrated by its showing a line of identity with a previously prepared, pure, antihuman $\mathrm{P}$ obtained from Dr. M. Frank. Fluorescent staining of the anti-P, factor B, C5, and IgD was performed with commercially obtained, fluorescein-conjugated rabbit antigoat Ig (Cappel Laboratories, Inc., Downingtown, $\mathrm{Pa}$.) or sheep antirabbit Ig (Progressive Laboratories, Baltimore, Md.).

Staining was performed after the tissues (patient skin, baby skin, or placenta) had been embedded in O.C.T. embedding compound (Lab-Tek Products, Div. Miles Laboratories, Inc., Naperville, Ill.), frozen in liquid $\mathrm{N}_{2}$, stored at $-70^{\circ} \mathrm{C}$, cut at $4 \mu \mathrm{m}$ in a cryostat, and rinsed for $5 \mathrm{~min}$ in phosphate-buffered saline (PBS), $\mathrm{pH}$ 7.4. The antisera (FITC labeled or unlabeled) were then applied to the tissue sections and incubated at room temperature in a moist chamber for $30 \mathrm{~min}$. They were then washed in five changes of PBS for $5 \mathrm{~min}$ each and, in the case of the unlabeled antisera, dried, and again incubated with the FITC-labeled, rabbit antigoat $\mathrm{Ig}$ or sheep antirabbit $\mathrm{Ig}$ for $30 \mathrm{~min}$. These sections were then washed five times with PBS. All sections were covered with $50 \%$ glycerin in PBS and a coverslip and viewed under a Leitz Ortholux II, epi-illuminated, fluorescent microscopy (E. Leitz, Inc., Rockleigh, N. J.).

Indirect IF staining, used to test sera for circulating antibodies to BM zone, was performed with the following substrates: normal human skin, normal human esophagus, normal guinea pig esophagus, and normal monkey esophagus. Details of this procedure can be found elsewhere (7).

The in vitro complement binding technique, described by Jordon et al. (8), was used to demonstrate and characterize the serum factor responsible for the binding of complement to the BM zone of the normal, stratified squamous epithelia. Briefly, the patients' sera, treated or untreated, were incubated for $30 \mathrm{~min}$ on the previously rinsed tissue sections. Each section was then washed five times in PBS, covered with a source of complement (fresh normal human serum, fresh normal guinea pig serum, or C4-deficient guinea pig serum in varying concentrations), and incubated for $30 \mathrm{~min}$. The sections were rinsed five times in PBS, and the remainder of the technique as described above for the direct or modified direct technique was used for the demonstration of binding of $\mathrm{Clq}, \mathrm{C} 4, \mathrm{C} 3, \mathrm{P}$, or factor $\mathrm{B}$ to the $\mathrm{BM}$ zone. When guinea pig sera were used as a source of complement, the sections were stained for fluorescence with a 1:40 dilution of a commercially obtained, FITC-labeled, goat antiguinea pig C3 (Cappel Laboratories, Inc.).

Comparison of $H G$ and bullous pemphigoid (BP) sera for in iitro IgG binding and in vitro complement fixation. The circulating antibody ( $\operatorname{IgG}$ ) titer and complement fixing 
ability of sera from six patients with BP (five of which were kindly provided by Dr. T. Provost) were determined for comparison with those of the sera from patients with HG. These six BP sera were chosen because they had previously been shown to have complement binding activity.

Sucrose density ultracentrifugation. $1 \mathrm{ml}$ of serum from patients 1 and 4 was applied to $10 \mathrm{ml}, 10-40 \% \mathrm{wt} / \mathrm{vol}$, continuous sucrose gradients prepared with the use of a Beckman density gradient former (Beckman Instruments, Inc., Spinco Div., Palo Alto, Calif.). The gradients were then centrifuged for $20 \mathrm{~h}$ in a Beckman L2-65B ultracentrifuge at $4^{\circ} \mathrm{C}, 100,000 \mathrm{~g}$, using an SW 40 swinging rotor (Beckman Instruments, Inc.). $0.5-\mathrm{ml}$ aliquots were then removed from the bottom of each tube and tested for complement binding activity, and by immunoelectrophoresis and radial immunodiffusion.

Chelation of serum with EDTA and ethyleneglycoltetracetic acid $(E G T A)$. The basic method of Fine et al. (9) was used to determine whether in vitro complement binding was proceeding via the classical or alternate pathway. The classical pathway requires $\mathrm{Ca}^{++}$and $\mathrm{Mg}^{++}$in order to proceed and the alternate pathway $\mathrm{Mg}^{++}$but not $\mathrm{Ca}^{++}$; EDTA chelates $\mathrm{Ca}^{++}$and $\mathrm{Mg}^{++}$, and EGTA chelates $\mathrm{Ca}^{++}$but little $\mathrm{Mg}^{++}$. EDTA was added to the patients' sera (1, 3, and 4) to yield a final concentration of $10 \mathrm{mM}$. The fresh normal human sera (NFS) which were used as a source of complement were treated with either nothing, EDTA, or EGTA to a final concentration of $10 \mathrm{mM}$. The chelated EGTAtreated sera were then reconstituted with $\mathrm{CaCl}_{2}$ or $\mathrm{MgCl}_{2}$ to a final concentration of $10 \mathrm{mM}$ of serum.

Scrum absorption studics. To determine whether or not the factor responsible for binding complement was an IgG, $0.1 \mathrm{ml}$ of serum from patient 1 was incubated with either $0.2 \mathrm{ml}$ normal goat serum, $0.2 \mathrm{ml}$ of specific goat antihuman IgG $(2.5 \mathrm{mg} / \mathrm{ml})$, or with $0.2 \mathrm{ml}$ goat antihuman $\operatorname{IgE}(2.3 \mathrm{mg} / \mathrm{ml})$ for $\frac{1}{2} \mathrm{~h}$ at $37^{\circ} \mathrm{C}$ and then overnight at $4^{\circ} \mathrm{C}$, and the precipitate spun down the next morning. The sera of patients 3 and 4 were incubated with either $0.2 \mathrm{ml}$ normal goat serum, goat antihuman $\mathrm{IgG}$, or goat antihuman IgM and treated in a similar manner. The supernates were then tested for complement binding factor by the in vitro complement binding technique and for IgG concentration by radial immunodiffusion.

Scrum immunoglobulin and complement levels. C4 and CH50 assays were determined by Dr. M. Frank on sera of patients 1 and 3 maintained at $-70^{\circ} \mathrm{C}$. C3, IgG, IgM, and IgA levels were determined by radial immunodiffusion; IgE levels were determined by Dr. A. Kaplan using a Phadebus radioallergoabsorbent test (Pharmacia Fine Chemicals, Inc., Piscataway, N. J.).

Papain digestion of $H G$ serum. $1 \mathrm{mg}$ of papain was added to $1 \mathrm{ml}$ of serum (patients 1,3 , and 4) containing $0.01 \mathrm{M}$ cysteine and $0.002 \mathrm{M}$ EDTA, and incubated for 8 $\mathrm{h}$ at $37^{\circ} \mathrm{C}$. Chloromercuribenzoate was added to a final concentration of $0.001 \mathrm{M}$, and the serum was then dialyzed against PBS for $20 \mathrm{~h}$. The cysteine, EDTA, and chloromercuribenzoate were added to another $1 \mathrm{ml}$ of serum which was then dialyzed and used as a control. The complement binding assay and indirect IF technique were then performed with varying dilutions of the digested and nondigested sera.

Controls. Sera from 13 pregnant women in all stages of pregnancy were tested for circulating antibodies to the BM zone and for the complement binding factor by indirect IF. Normal and lesional skin from four women in the third trimester of pregnancy, all with widespread, pruritic dermatoses, were examined for in vivo bound Ig and $\mathrm{C}$.

\section{RESULTS}

\section{In vivo binding of $\mathrm{Ig}$ and $\mathrm{C}$}

Immunoglobulin deposits. Linear IgG deposits at the basement membrane zone were seen in normal-appearing and lesional skin of patients 1 and 2, in normal-appearing skin of patient 3 , and only in lesional skin of patient 5; they were not found in patient 4 . These deposits in the normal-appearing skin of patient 1 were present on five biopsies taken during pregnancy and in one taken 2 days postpartum, but not in those taken $3 \mathrm{wk}$ and 4 mo postpartum. They were also demonstrated in the skin of patient 3 on five biopsies taken during pregnancy. Iclentical $\operatorname{IgE}$ deposits were seen in the normal and lesional skin of patient 1 coincident with the IgG. None of the Ig or complement deposits was seen in areas where subepidermal blisters occurred. No Ig deposits were seen in the skin of patient 4 , nor were there any other Ig deposits in the skin specimens studied (Table I).

Complement dcposits. When present, complement components were invariably deposited as linear bands at the $\mathrm{BM}$ zone. Intense $\mathrm{C} 3$ deposits were seen on all biopsies of every patient, both in normal-appearing and in lesional skin (Fig. 1). Moreover, patient 1 had persistance of $\mathrm{C} 3$ for as long as 6 mo postpartum, both before and after taking Ortho-Novum 1/50. C3 was found in the normal-appearing skin of the 6-wk-old child of patient 2. Other complement components were seen less consistently. The alternate pathway components $\mathrm{P}$ and factor $B$ were present in normal and lesional skin on all biopsies taken from patient 1 throughout her pregnancy and up to $3 \mathrm{wk}$ after delivery. They were also found in the normal skin of patient 2 , taken $6 \mathrm{wk}$ postpartum, and in lesional skin of patient 3. Factor B, but not $P$, was found in the lesional skin of patient 2 , and $P$, but not factor $B$, in the normal skin of patient 3 ( Table II).

Controls. None of the skin, either lesional or normal, from the four other pregnant patients studied showed in vivo binding of $\mathrm{IgG}$ or any of the complement components; nor did any of 40 biopsies of normal or lesional skin from patients with various nonvesicular eruptions show any in vivo binding of complement components.

Placcuta. The placentas of patients with $\mathrm{HG}$ and of normals showed no differences with regard to $\mathrm{Ig}$ or $\mathrm{C} 3$ deposition. There was in vivo bound $\mathrm{IgG}$ at $\mathrm{BM}$ of the villi of all placentas studied, in accord with published studies $(10)$.

\section{Serum studies}

Indirect IF studies. Indirect IF studies of the serum of each of the patients, of the infant and cord blood in case 1 , and of the cord blood in case 3 yielded few positive results with regard to $\mathrm{Ig}$. In the serum of only 
TABLE I

Direct IF of Skin for IgG Deposition

\begin{tabular}{clccc}
\hline & & & \multicolumn{2}{c}{ Skin } \\
\cline { 3 - 5 } Patient no. & & Rx & Lesional & Normal \\
\hline 1 & Pregnant & - & + & + \\
& Postpartum, 2 days & Prednisone & NL* & + \\
& Postpartum, 3 wk & Prednisone & NL & - \\
& Postpartum, 4 mo & - & NL & - \\
& Postpartum, 5 mo & Ortho-Novum & - & NT \\
2 & Postpartum, 6 wk & - & + & + \\
2 (Baby) & 8-wk-old & - & NL & - \\
3 & Pregnant & - & - & + \\
4 & Pregnant & Prednisone & NL & + \\
5 & Postabortion, 1 wk & Prednisone & - & - \\
Disease controls (4) & Pregnant & - & + & - \\
\hline
\end{tabular}

* No lesions present.

$\ddagger$ Not tested.

patient 1 was there a circulating IgG which bound to the BM zone of normal skin or esophagus. It could be detected at no greater than a 1:10 dilution and was not found after delivery.

Complement binding $(H G)$ factor. Complement binding $(\mathrm{HG})$ factor was detected in the sera of the first four patients and in the cord blood from patient 3 (Table III). It was not detected in the cord blood or serum from the baby of patient 1 . The dilution at which each serum bound C3 from a 1:10 dilution of fresh human serum did not vary throughout the pregnancy of patient 1 or 3 (Table III). It was no longer detectable in the

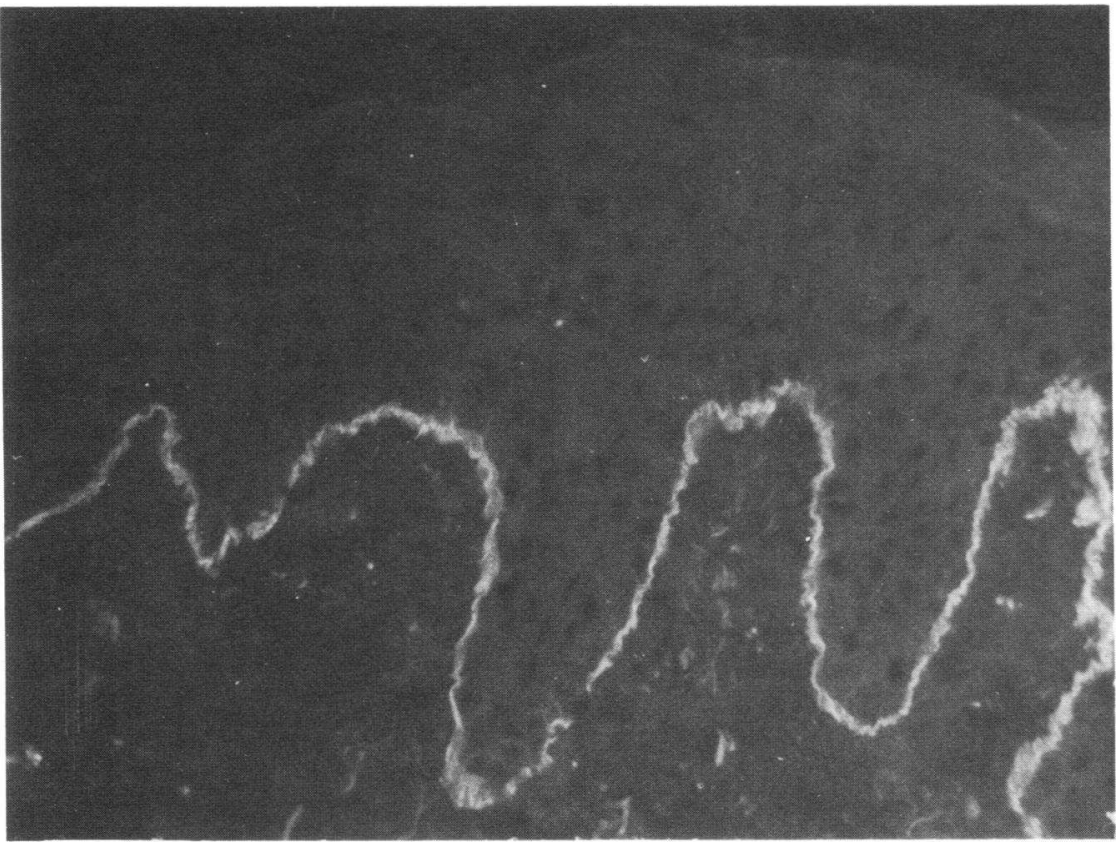

FIGURE $1 \mathrm{HG}$; complement binding. Intense $\mathrm{C} 3$ staining is present at the $\mathrm{BM}$ zone of an area adjacent to lesional skin $(\times 250)$. 
TABLE II

Direct IF of Skin for Complement Deposition

\begin{tabular}{|c|c|c|c|c|c|c|c|c|c|}
\hline Patient no. & & $\mathbf{R x}$ & Skin & $\mathrm{C} 3$ & $\mathrm{C} 5$ & P* & $\mathrm{B} \ddagger$ & $\mathrm{C} 1 \mathrm{q}$ & $\mathrm{C} 4$ \\
\hline \multirow[t]{6}{*}{1} & Pregnant & - & Lesional & + & NT§ & + & + & + & + \\
\hline & Pregnant & - & Normal & + & NT & + & + & + & + \\
\hline & Postpartum, 2 days & Prednisone & Normal & + & NT & + & + & + & + \\
\hline & Postpartum, $3 \mathrm{wk}$ & Prednisone & Normal & + & NT & + & + & - & - \\
\hline & Postpartum, $4 \mathrm{mo}$ & - & Normal & + & NT & - & - & - & - \\
\hline & Postpartum, $5 \mathrm{mo}$ & Ortho-Novum & Lesional & + & + & - & - & - & - \\
\hline \multirow[t]{2}{*}{2} & Postpartum, $6 \mathrm{wk}$ & - & Lesional & + & NT & - & + & + & + \\
\hline & Postpartum, $6 \mathrm{wk}$ & - & Normal & + & NT & + & + & + & + \\
\hline 2 (Baby) & 8-wk-old & - & Normal & + & NT & - & - & - & + \\
\hline \multirow[t]{3}{*}{3} & Pregnant & - & Lesional & + & NT & + & + & - & - \\
\hline & Pregnant & - & Normal & + & NT & - & - & - & - \\
\hline & Pregnant & Prednisone & Normal & + & + & + & - & - & - \\
\hline \multirow[t]{2}{*}{4} & Postabortion, $1 \mathrm{wk}$ & Prednisone & Lesional & + & + & - & - & - & - \\
\hline & Postabortion, $1 \mathrm{wk}$ & Prednisone & Normal & + & - & - & - & - & - \\
\hline \multirow[t]{2}{*}{5} & Pregnant & - & Lesional & + & - & NT & NT & NT & NT \\
\hline & Pregnant & - & Normal & + & - & - & - & - & - \\
\hline \multirow[t]{2}{*}{ Controls (4) } & Pregnant & - & Lesional & - & NT & NT & NT & NT & NT \\
\hline & Pregnant & - & Normal & - & NT & NT & NT & NT & NT \\
\hline
\end{tabular}

* Properdin.

$\ddagger$ Factor B.

$\S$ Not tested.

serum of patient 14 mo postpartum, at a time when in vivo bound $\mathrm{C} 3$ could be detected easily. None of the sera obtained from normal pregnant women or from those with other clermatoses associated with pregnancy contained the HG factor. The HG factor could be detected only when normal human substrates (skin or esophagus) were used; it could not be detected with monkey or guinea pig esophagus.

When the patients' fresh sera were used as a source of both the HG factor and of functionally active C3 in a two-step procedure, C3 was usually but not always, bound at the BM zone. However, when the three-step technique was used with a $1: 10$ dilution of NFS as the second step, C3 was invariably bound. When the $\mathrm{HG}$ serum (patient 1) was heated to $60^{\circ} \mathrm{C}$ for $30 \mathrm{~min}$ or $1 \mathrm{hr}$ and a 1:10 dilution of NFS used, C3 was also invariably bound. If both $\mathrm{HG}$ and NFS were heated to $56^{\circ} \mathrm{C}$ for $30 \mathrm{~min}$, on the other hand, there was no $\mathrm{C} 3$ binding.

\section{Comparison of HG and BP serum antibody titers} and complement binding titers

The BP sera had complement binding titers ranging from 2 to 16 and antibody titers of greater than 160 . This is in contrast to the findings in the HG sera where the complement binding titers were invariably higher than the circulating antibody titers.

\section{Early complement component binding}

When the sera of patients 1 or 4 were used as the first step in the complement binding technique, NFS (either undiluted or diluted $1: 10$ ) as the second step, and IITC-labeled anti-C1q, or $\mathrm{C} 4$ as the third step, binding of both $\mathrm{Clq}$ and $\mathrm{C} 4$ could be demonstrated (Table IV). When unlabeled goat anti-P or rabbit antifactor B was used as the third step and labeled sheep antirabbit Ig or rabbit antigoat Ig used as the fourth step, binding of neither could be demonstrated (Table IV).

The use of normal and C4-deficient guinea pig serum

C3 in normal guinea pig serum (1:10 dilution) was also bound by the HG factor in the complement binding test. However, when C4-deficient guinea pig serum (1:10 dilution) was used as a source of complement, there was no $\mathrm{C} 3$ binding by the sera of patients 1 and 3 . When the C4-deficient and normal guinea pig sera were mixed together (final dilution of each 1:10) C3 was bound at the BM zone of normal skin. 
TABLE III

In Vitro C3 Binding Using Normal Human Skin as Substrate

\begin{tabular}{|c|c|c|c|c|}
\hline Patient & Date & & $\mathrm{Rx}$ & $\begin{array}{c}\text { C3 binding } \\
\text { titer }\end{array}$ \\
\hline \multirow[t]{8}{*}{1} & $12 / 18 / 74$ & Pregnant & None & 40 \\
\hline & $1 / 5 / 75$ & Pregnant & Prednisone & 40 \\
\hline & $1 / 22 / 75$ & Pregnant & Prednisone & 40 \\
\hline & $3 / 5 / 75$ & Pregnant & Prednisone & 40 \\
\hline & $3 / 19 / 75$ & Postpartum, 1 day & Prednisone & 20 \\
\hline & $4 / 9 / 75$ & Postpartum, $3 \mathrm{wk}$ & Prednisone & 10 \\
\hline & $7 / 29 / 75$ & Postpartum, $4 \mathrm{mo}$ & None & -* \\
\hline & $8 / 29 / 75$ & Postpartum, $5 \mathrm{mo}$ & Ortho-Novum & —* $^{*}$ \\
\hline 1 (Cord serum) & $3 / 18 / 75$ & & & $-\ddagger$ \\
\hline 1 (Baby serum) & $3 / 20 / 75$ & 2-day-old & None & $-\ddagger$ \\
\hline 2 & $3 / 5 / 75$ & Postpartum, $6 \mathrm{wk}$ & None & Neat \\
\hline \multirow[t]{5}{*}{3} & $5 / 16 / 75$ & Pregnant & None & 8 \\
\hline & $5 / 27 / 75$ & Pregnant & Prednisone & 4 \\
\hline & $6 / 11 / 75$ & Pregnant & Prednisone & 8 \\
\hline & $7 / 9 / 75$ & Pregnant & Prednisone & 8 \\
\hline & $9 / 18 / 75$ & Postpartum, $2 \frac{1}{2}$ wk & Prednisone & 2 \\
\hline 3 (Cord serum) & $8 / 24 / 75$ & & & 2 \\
\hline 4 & $8 / 26 / 75$ & Postabortion, $1 \mathrm{wk}$ & Prednisone & 10 \\
\hline 5 & $10 / 8 / 75$ & Pregnant & None & - $^{*}$ \\
\hline Controls (10) & & Pregnant & None & - $^{*}$ \\
\hline
\end{tabular}

* Negative neat.

$\ddagger$ Negative at 1:10 dilution.

\section{Chelation of serum with EDTA or EGTA}

When EDTA-treated sera of patients 1, 3, and 4 were used in the first step of the complement binding technique on normal human skin and a $1: 10$ dilution of NFS in the second step, $\mathrm{C} 3$ was bound at the BMI zone. If NFS treated with EDTA, EGTA, or EGTA- $\mathrm{Mg}^{++}$was used in the second step, C 3 was not bound. When the EGTAtreated NFS was reconstituted with $\mathrm{CaCl}_{2}$, there was $\mathrm{C} 3$ binding at the BM zone (Table V).

TABLE IV

In Vitro Complement Binding Technique; the Early Components

\begin{tabular}{lccccc}
\hline Patient & $\begin{array}{c}\text { Serum } \\
\text { dilution }\end{array}$ & Properdin & Factor B & C1q & C4 \\
\hline 1 & $1: 10$ & - & - & + & + \\
1 (Cord) & $1: 10$ & - & - & - & - \\
1 (Baby) & $1: 10$ & - & - & - & - \\
2 & $1: 10$ & - & - & - & - \\
4 & Neat & - & - & + & + \\
& $1: 2$ & - & - & - & + \\
\hline
\end{tabular}

\section{Specific immunoabsorption studies}

The supernatant fluids which remained after incubation of the serum from patient 1 with normal goat serum, goat antihuman $\operatorname{IgG}$, or goat antihuman $\operatorname{IgE}$ contained $1,500 \mathrm{mg} / \mathrm{dl}, 300 \mathrm{mg} / \mathrm{dl}$ and $1,400 \mathrm{mg} / \mathrm{dl}$ of $\mathrm{IgG}$ respec-

TABLE V

Inactivation of Complement Pathways;* Indirect IF Using Normal Skin as Substrate

\begin{tabular}{ccc}
\hline \multicolumn{2}{c}{ Chelation } & \\
\cline { 2 - 3 } HG serum & Normal fresh serum & C3 binding \\
\hline EDTA $\ddagger$ & - & + \\
EDTA & EDTA & - \\
EDTA & EGTA & - \\
EDTA & EGTA $+\mathrm{MgCl}_{2}$ & - \\
EDTA & EGTA $+\mathrm{CaCl}_{2}$ & + \\
\hline
\end{tabular}

* Classical pathway requires $\mathrm{Ca}^{++}$and $\mathrm{Mg}^{++}$; alternate pathway requires $\mathrm{Mg}^{++}$but not $\mathrm{Ca}^{++}$.

$\ddagger$ Binds $\mathrm{Ca}^{++}$and $\mathrm{Mg}^{++}$.

$\S$ Binds $\mathrm{Ca}^{++}$but little $\mathrm{Mg}^{++}$. 
tively; the goat antihuman IgG therefore absorbed out $80 \%$ of the total IgG. The HG serum absorbed with goat antihuman IgG no longer had complement binding activity while the other two samples, that absorbed with goat antihuman $\operatorname{IgE}$ and that incubated with normal goat serum retained their complement binding activity. The sera of patients 3 and 4 did not retain their complement binding ability after incubation with goat antihuman IgG while those incubated with normal goat serum or goat antihuman IgM were still able to bind complement.

\section{Sucrose gradient ultracentrifugation}

C 3 binding by the serum of patient 1 could be detected in fractions 15 through 20 (22 fractions total); it was strongest in fractions 17 and 18. These six fractions all contained IgG as determined by immunoelectrophoresis whereas fraction 5, negative for C3 binding activity, did not. C3 binding by the serum of patient 3 could be detected only in fraction 18 (19 fractions total). This fraction contained IgG as determined by radial immunodiffusion.

\section{Papain digestion of HG serum}

Papain digested serum from patient 1 did not bind C3 in the complement binding test. The Fab fragment of IgG did, however, bind to the BM zone as demonstrated by the conventional indirect IF test using FITC-labeled anti-IgG. Papain digested sera from patients 3 and 4 did not bind $\mathrm{C} 3$ nor did the Fab fragment bind to the $\mathrm{BM}$ zone. These undigested sera, however, did not previously contain antibodies which could be demonstrated by conventional indirect IF.

\section{Serum immunoglobulin and complement levels}

Serum IgG, $\operatorname{Ig} A, \operatorname{Ig} M, \operatorname{IgE}$, and C3 levels were normal in all five patients. Serum $\mathrm{C} 4$ and $\mathrm{CH}_{50}$ in the patients tested were also normal.

\section{DISCUSSION}

C3 deposition at the $\mathrm{BM}$ zone of normal and nonbullous lesional skin with or without IgG deposition at the same site is a constant finding in patients with $\mathrm{HG}$. In this regard our findings in 5 patients are in agreement with the results of the immunologic studies of 12 other $\mathrm{HG}$ patients reported to date.

The in vitro studies of the complement binding factor in the sera of these patients are not in keeping with those of Provost and Tomasi (1), who state that the serum factor in HG capable of depositing C3 on BM of normal human skin is not an Ig, is present only during active disease, and is thermolabile. Our data using specific absorption studies, papain digestion, sucrose gradient ultracentrifugation, heat inactivation, and indirect IF would strongly suggest that the HG factor is a thermostabile IgG. The serum level of complement binding factor, moreover, does not vary during the course of the disease, as the titers did not change until after delivery in those tested, despite the fact that $24 \mathrm{~h}$ after treatment of patients 1,3 , and 4 with prednisone, symptoms abated, and 7-8 days thereafter the clinical disease resolved.

While there is solid evidence that HG factor is transferred across the placenta in most instances (patients 2 and 3 ), the cord and baby blood in case 1 , where the highest titer of this factor was found, did not contain demonstrable levels; this observation is at present unexplained. The possibility that it was trapped within the placenta was explored, but increased placental IgG deposition could not be discerned over and above the high background levels of two normal placentas, and C3 could not be identified as specifically bound to the villous $B M$ on direct IF.

The in vivo binding of early complement components necessary for the activation of the classical ( $\mathrm{Clq}, \mathrm{C} 4)$ and alternate $(P$, factor $B$ ) complement pathways implicates both routes in the activation or binding of $\mathrm{C} 3$ at the BM zone. All studies of in vitro complement binding by the $\mathrm{HG}$ factor, however, demonstrated activation of only the classical pathway: (a) C4-deficient guinea pig serum, containing an incomplete classical complement pathway and, therefore, activatable only via the alternate pathway (11), was an inadequate source of complement for binding by the $\mathrm{HG}$ factor; (b) $\mathrm{Clq}$ and $\mathrm{C} 4$, classical pathway components, but not $\mathrm{P}$ or factor $\mathrm{B}$, alternate pathway components, were bound with $\mathrm{C} 3$; and $(c)$ inactivation of both classical and alternate complement pathways in the complement source by EDTA, and inactivation of the classical pathway in the complement source by EGTA prevented complement binding, while reconstitution of the classical pathway in the EGTA-chelated complement source by addition of $\mathrm{CaCl}_{2}$ reactivated complement binding. While the discrepancy between in vivo and in vitro studies has not been satisfactorily resolved, two likely explanations exist. Firstly, it may be that the techniques available to study in vitro binding of complement by the $\mathrm{HG}$ factor may not be sensitive enough to discern alternate pathway activation. Secondly, the alternate pathway may be activated in vivo via the C3 amplication loop, in which C3, however generated, feeds back to trigger further complement activation via the alternate pathway, thus significantly augmenting its own activity (12); this amplication loop may not be adequately stimulated under the specific conditions of the in vitro investigations.

Although much has been learned about the immunologic correlates of $\mathrm{HG}$, a pathogenetic role for IgG and complement has not yet been demonstrated. Compelling 
evidence supporting their involvement in the production of lesions in BP has recently been reviewed (13). Further studies on identification, purification, and characterization of the antigen responsible for evoking the antibody responses in both HG and BP are needed.

Nosologically, HG may be more closely related to BP than it is to either dermatitis herpetiformis or erythema multiforme. The immunopathology is similar in that $\mathrm{IgG}$ and $\mathrm{C} 3$ are bound in vivo at the BM zone of lesional and normal skin in both diseases. There are, however, distinct light and electron microscopic differences as well as differences in the ultrastructural localization of in vivo bound C3 in the two diseases (14). Moreover, the complement binding ability of the anti-BM zone $\operatorname{IgG}$ in $\mathrm{BP}$ is found in lower titer than its demonstrable antibody activity; the converse is true in HG. The patient population at risk, provocative factors (e.g. oral contraceptives), and the universal tendency toward remission after and between pregnancies further serve to separate $H G$ as a distinct entity.

\section{ACKNOWLEDGMENTS}

We wish to thank Ms. Laura Gazze for her excellent technical assistance. We also express our appreciation to Doctors Robert Katz, Gary Cage, W. Michael Gould, Robert Walther, and Lee Blakely for referring their patients.

\section{REFERENCES}

1. Provost, T. T., and T. B. Tomasi, Jr. 1973. Evidence for complement activation via the alternate pathway in skin diseases I. Herpes gestationis, systemic lupus erythematosus, and bullous pemphigoid. J. Clin. Invest. 52: 1779-1787.

2. Jablonska, S., T. P. Chorzelski, E. H. Beutner, E. Maciejowska, and G. Rzesa. 1975. Immunologic phenomena in herpes gestationis. Arch. Dermatol. Forsch. 252: 267-274.
3. Kocsis, M., T. L. Eeg, G. Husby, and G. Rajka. 1975. Immunofluorescence studies in herpes gestationis. Acta Derm-Venereol. 55 : 25-29.

4. Carruthers, J. A., and M. M. Black. 1975. Immunopathologic findings in herpes gestationis. Br. J. Dermatol. 93 (Suppl. II) : 17. (Abstr.)

5. Bushkell, L. L., R. E. Jordon, and R. W. Goltz. 1974. Herpes gestationis. New immunologic findings. Arch. Dermatol. 110: 65-69.

5A. Hertz, K. C., S. I. Katz, J. Maize, and A. B. Ackerman. 1976. Herpes gestationis. A clinical pathologic study. Arch. Dermatol. In press.

6. Wardlaw, A. C., and L. Pillemer. 1956. The properdin system and immunity. V. The bacteriocidal activity of the properdin system. J. Exp. Med. 103: 553-575.

7. Katz, S. I., K. M. Halprin, and T. M. Inderbitzin. 1969. The use of human skin for the detection of antiepithelial autoantibodies. A diagnostic and prognostic test. J. Invest. Dermatol. 53: 390-399.

8. Jordon, R. E., W. M. Sams, Jr., and E. H. Beutner. 1969. Complement immunofluorescent staining in bullous pemphigoid. J. Lab. Clin. Med. 74: 548-556.

9. Fine, D. P., S. R. Marney, Jr., D. G. Colley, J. S. Sergent, and R. M. Des Prez. 1972. C3 shunt activation in human serum chelated with EGTA J. Immunol. 109 : 807-809.

10. Faulk, W. P., M. Jeannet, W. D. Creighton, and A. Carbonara. 1974. Immunological studies of the human placenta. Characterization of immunoglobulins on trophoblastic basement membranes. J. Clin. Invest. 54: 10111019.

11. Ellman, L., I. Green, F. Judge, and M. M. Frank. 1971. In vivo studies in C4-deficient guinea pigs. J. Exp. Med. 134: 162-175.

12. Fearon, D. T., and K. F. Austen. 1975. Interaction of properdin with $\mathrm{C} 3 \mathrm{~b}$ : Participation of properdin in the alternative pathway amplification loop. Fed. Proc. 34: 981. (Abstr.)

13. Jordon, R. E. 1975. Complement activation in bullous skin diseases. J. Invest. Dermatol. 65: 162-169.

14. Yaoita, H., M. Gullino, and S. I. Katz. 1976. Herpes gestationis. Ultrastructure and ultrastructural localization of in vivo bound C3. J. Invest. Dermatol. In press. 